Article

\title{
Preservation Strategies for Southern Morocco's At-Risk Built Heritage
}

\author{
Pablo Rodríguez-Navarro * (i) and Teresa Gil Piqueras * \\ Instituto Universitario de Restauración del Patrimonio, Universitat Politècnica de València, 46022 Valencia, Spain \\ * Correspondence: rodriguez@upv.es (P.R.-N.); tgil@ega.upv.es (T.G.P.)
}

Received: 9 December 2017; Accepted: 23 January 2018; Published: 26 January 2018

\begin{abstract}
Morocco has a vernacular architectural heritage of recognized value, which constitutes an indissoluble part of its cultural legacy. In the south of the country, specifically in the High Atlas mountain range and the pre-Saharan oases, we mainly find earth constructions of an incomparable landscape integration and plasticity. However, the political and social changes of the last decades are favoring the abandonment of these constructions, placing many of them at risk of disappearing. The objective of this contribution is to reveal the characteristics and weaknesses that the new constructions present today. The method used has consisted in analyzing the preservation actions that are being carried out, both by the Moroccan public administration and by private individuals, including those developed by the authors through documentation, cataloging, virtualization, and restoration.
\end{abstract}

Keywords: at-risk heritage; earthen architecture; graphic surveying; 3D modelling; Morocco

\section{Introduction}

The Moroccan territory stands out among other things for its great landscape diversity. As we travel from North to South, the landscape slowly transforms, taking us through diverse natural environments, ranging from the green mountains of the Rif and the immense cultivable areas of the North, to the large extensions of stony, arid and dry land of the South, known in Arabic as hamada, which are reached once we cross the High Atlas.

The differences found on both sides, at the physical and at the climatic level, condition the communities' adoption of different habitat solutions within the same cultural tradition. In the North, where we find large arable green areas, irrigated by rivers with wide riverbeds that carry water throughout the year and enjoy a temperate-warm Mediterranean climate, it is common to find the population living in dwellings located in isolation or forming small groupings, distributed in a dispersed way throughout its extension. On the other hand, in the southern lands, characterized by a pre-desert climate, having very poorly developed and even rocky soils, along with water scarcity, the population is obliged to live grouped along the great pre-Saharan valleys and the oases that are generated thanks to the construction of khetaras, their existence being conditioned to the presence of water.

In any case, this architecture characterizing the South Moroccan landscape is executed with rammed earth, a tradition imported centuries ago from other latitudes which today is considered to be a technique directly linked to the Berber culture. In these environments, we find large fortresses [1] ('ksar' or 'ksour' in pl.) where many families coexist under the name of the same tribe, to fortified dwellings housing a single family ('kasbah' or 'kasbahs' in pl.), that sometimes can be composed of as many members as those living in a fortress [2].

In general, the 'kasbah' is characterized by having a square floor topped by slender towers in the corners, which confer it a greater sensation of slenderness at the time they strengthen its structure [3]. 
The 'kasbahs' are usually integrated by a ground floor and two heights, which are surpassed by the towers' upper floor, which have three stories. A typical 'kasbah' is organized as follows: after accessing its interior through a door that is placed in the middle of one of its cloths, we find a vestibule in whose axis the staircase is located, generating two spaces on both sides where different rooms for storage and stable are found. The first and second floors follow the same layout; around the central nucleus of the staircase, a corridor gives access to new rooms for family use up to the rooftop, from where the interior of the last section of the towers can be accessed. The use of the roof and the towers' top floor is intended for drying food and the housing of domestic animals [4].

In the case of the 'ksour', despite being constructions where the Muslim culture is very present, its urban organization is far from the known archetypes of the Islamic city $[5,6]$, which define it as a city characterized by its spontaneous character. In this case, we find planned cities, in which no element is left to chance, fulfilling three main functions (Figure 1):

- Defensive function: seeking protection, the city is built closed, usually being surrounded by a wall and with one or two entrances. Additionally, the wall is endowed with watchtowers, located mainly in the corners and flanking the main access, generally located in the area most susceptible to possible attacks. The entrance has defensive features as well, being elbow-bent or equipped with a double door.

- Social function: the existence of community-use services in cities is a common feature, although not all of them come to house them. The most characteristic are usually:

- The mosque, next to the access door where the muezzin calls the population to pray.

- The public baths, where the population comes to perform their personal hygiene, as established by religion itself.

- The square, where the market is located and also where men meet to establish social relations.

- The entrance, which has multiple uses, being a guarded access, is part of the city's defensive system, at the time it is used as a meeting place for the representatives of the 'ksar' ('jamaâ') to deal with issues that affect the relations of its inhabitants. Finally, in some cases, this space was used as a place to accommodate travelers or merchants traveling along the caravan route.

- Habitability function: within a 'ksar', the dwellings follow a generally common layout. They are organized in a variety of similar dimensions according to the distribution of streets. They are small and without outdoor windows. A single opening in the roof provides ventilation and lighting. Normally, they are laid out in two stories, with the stairs reaching the deck. The fulfillment of specific needs to be covered is arranged as follows: livestock, or other animals of domestic use, are found in the bottom floor along the necessary vegetables for their feeding. The family area is located on the first floor, and occasionally some areas serve as a grain stores. The rooftop, which is accessed through a small shed, is used for drying foods [7].

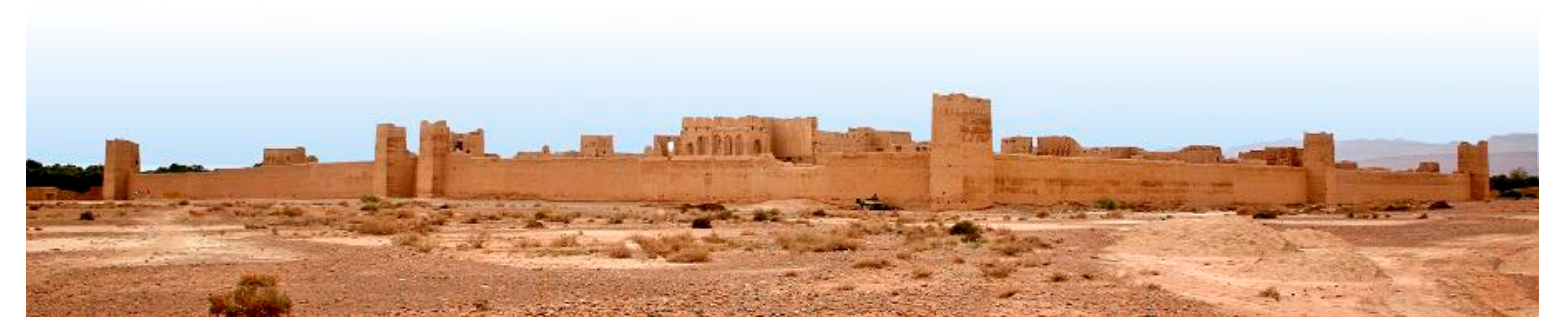

Figure 1. Sidi Bou Abdellah Ksar. Mdagra Oasis.

As for the habitability conditions of the 'ksar', its insertion on the territory, as well as its urban structure, play a very important role: the knowledge of the prevailing winds, the choice of high places 
close to the cultivable areas, the disposition of the entrances, as well as the streets' paving with the exception of their crossings, provide a sustainable air conditioning system which protects them from the harsh meteorological conditions, improving their quality of life.

\section{Sequential Abandonment of the Earth Habitat}

In recent years, the changes in the needs and ways of living of the local population are having an important impact on the traditional habitat, since in many cases the local population is leaving their homes and moving into new isolated concrete block buildings located in the outskirts of cities or even in the vicinity of the 'ksar'. This new way of life implies, on the one hand, the lack of maintenance of traditional dwelling and, ultimately, an unsustainable acceleration of their degradation process while, on the other hand, it entails a loss of quality of life, being poorly constructed housing due to the lack of knowledge of the construction techniques in the North hemisphere's countries, and the use of low quality material, far from the production and quality controls to which they are submitted in other places.

In short, the vernacular heritage of southern Morocco is at risk regardless of the area in which we find ourselves, abandonment being a pressing danger [8]. It is therefore a vulnerable heritage [9], in which resulting deterioration endangers the existence of this vernacular architecture, whose origin is lost in time. The loss of its architectural models, to favor other non-native ones, entails the transformation of the cultural landscape so characteristic of this country. Therefore, it is necessary to establish strategies for the preservation and enhancement of this traditional architecture, advancing the knowledge of their typology, materials, and traditional construction techniques.

\section{Preservation Strategies}

The deterioration of much southern Morocco's heritage is leading to its irreversible demise (Figure 2). To the list of problems that we have mentioned previously, we must add the fact that we are speaking of thousands of constructions. This vast amount makes their total recovery and maintennce an unfeasible, utopian idea. Thus, the various actions carried out attempt to preserve some examples of this magnificent manifestation of their culture, as a milestone, to ensure their continuity for future generations. These actions arise from both the public administration and private initiatives.

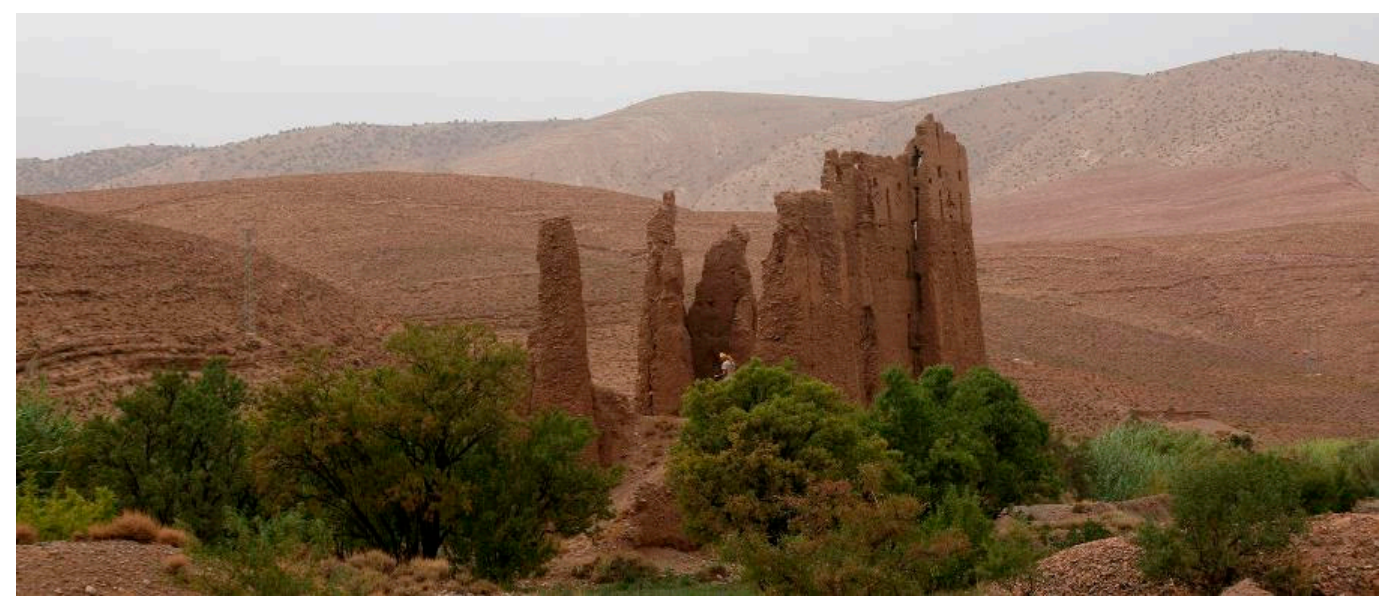

Figure 2. The Water Guardian Kasbah, Mgoum Valley. High Atlas.

\subsection{Actions Carried out by the Kingdom of Morocco's Administration}

\subsubsection{Ministry of Housing and Urban Policy}

As we have already mentioned, the problem of migration in search of better living conditions generates a population flow that beginning at the 'ksar' to go to the city, where it is easier to find 
employment and services. This makes the 'ksour' located in the vicinity of cities (most of these cities were built under the French protectorate) retain a high population density. For this reason, the Moroccan Ministry of Housing [10] takes action in many of these 'ksour' with the intention of consolidating their general structures and improving security and living conditions. At this point, it pays to mention that these actions are not carried out under the Ministry of Culture, so they are not planned or executed with the aim of preserving a cultural vernacular heritage in accordance with the criteria of this type of architecture. On the contrary, the criterion is purely related to housing policy which, on the other hand, is essential, since the people who inhabit them need to have a proper and safe place to live.

Thus, the actions are focused on the repair, reinforcement, and construction of support walls, beams, floorings, street paving; all of these with 'modern' materials based on concrete and steel. Nonetheless, the projects try to attain a finish that, at least visually, integrate the intervention with the vernacular environment, although they do not always achieve it (Figure 3).

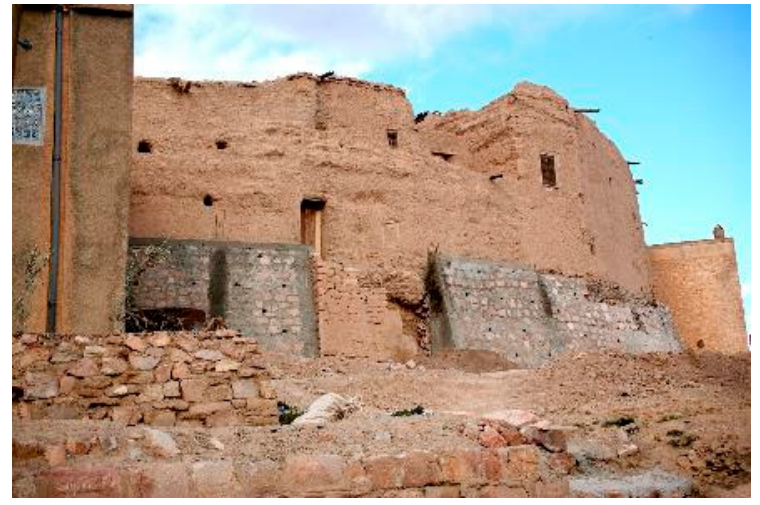

(a)

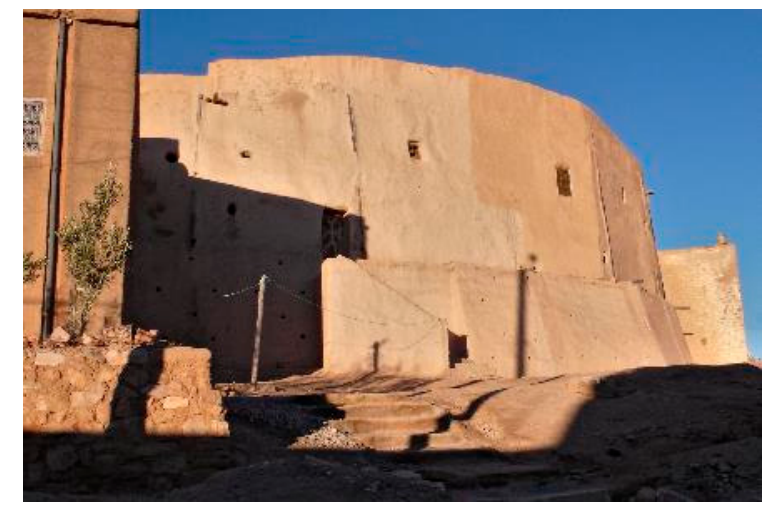

(b)

Figure 3. Restoration of the Tachaouite Ksar. (a) During the restoration work; (b) Final result.

\subsubsection{Center for Conservation and Restoration of Atlas and Sub-Atlas Architectural} Heritage (CERKAS)

The CERKAS [11] is a public institution under the Ministry of Culture, in its General Directorate of Cultural Heritage, and was created by decree of this Ministry, of 3 January 1990 (B. O. Number 4062 of 5 September 1990, p. 470). Its headquarters is located in the 'kasbah' of Taourirt, in the city of Ouarzazate. The architectural heritage under its tutelage comprises all the historic buildings and monuments of the Atlas and the sub-Saharan and Saharan areas, whether they are stone or earth constructions. It also includes isolated buildings such as 'kasbahs', granaries, and other communal ones like the 'ksour'. It concerns, in general, all the religious, military, or civil architecture of this region.

CERKAS' main aim is precisely to preserve the architectural heritage of Southern Morocco, so it has the following specific objectives [http://cerkas.org/wordpress/]:

- Rehabilitate and improve the architectural heritage of the Atlas and Sub-Atlas areas with socio-cultural purposes in collaboration with relevant bodies and authorities.

- Establish programs to safeguard buildings and architectural ensembles considered as the country's cultural property.

- Carry out technical, sociological, ethnological, or other studies that advance knowledge of the traditional architectures of the Atlas and pre-Saharan areas.

- Publish and disseminate information regarding the architectural heritage of Southern Morocco in the form of printed documents or audiovisual materials.

- Collaborate in comparative studies on the earth architecture, especially in the Atlas and pre-Saharan regions. 
- Establish and maintain collaborations with national or international institutions with a similar vocation.

The initiative to create the CERKAS 27 years ago and its objectives are one of the best initiatives there could have been implemented for the preservation of this particular heritage [12,13]. However, this whole of buildings would overwhelm any institution as powerful as it was; moreover, the CERKAS has to date worked with scarce resources, both human and economic, so it has been further limited in its actions.

In view of this situation, the different administrators have opted, as it could not be otherwise, for selecting their actions in order not to disperse their resources. The criteria seem to be oriented by historical, heritage, or architectural significance of each building, having made four interventions in these years:

- Ouarzazate. Kasbah of Taourirt.

- Ait Benhaddou (Figure 4a).

- Azilal region. Community granaries of Fakhor and Sidi Moussa.

- Zagora. Tamnougalte Ksar.

- Ouarzazate. Community granary of Ighrem N'ougdal. Community granary of Tazleft.

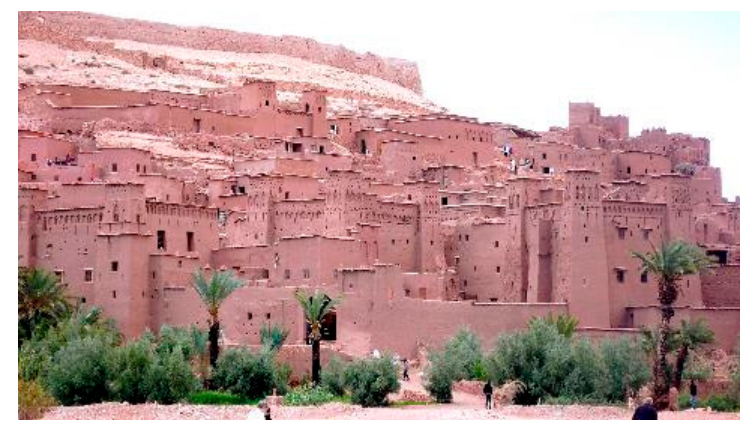

(a)

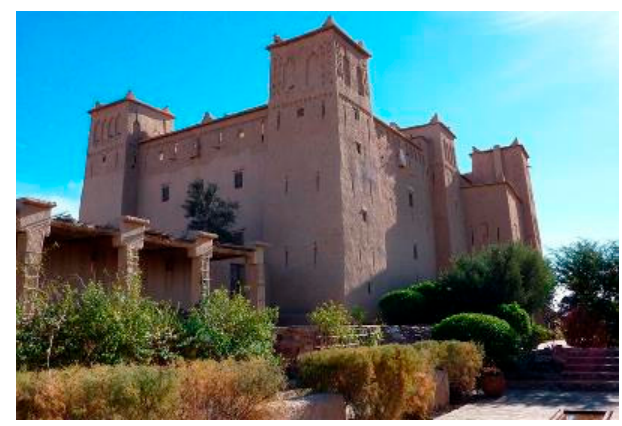

(b)

Figure 4. Two examples of kasbah restorations. (a) Ait Ben Haddou. UNESCO Word Heritage Site; (b) Kasbah of Ait Ben Moro. Skuora.

These are all exemplary interventions, but they seem to us very few for the great existing patrimony, their immeasurable value, and even more if we take into account the speed at which they are disappearing.

\subsection{Actions Carried out by Particular Initiatives}

We find other constructions that have been restored by private initiatives, mostly by tourism entrepreneurs. These constructions, mostly 'kasbahs' but also 'ksour' or 'riads' in the medinas [14], have followed the criteria of preservation of vernacular work, of culture, treating these earth buildings as architectural heritage. The objective is to restore them in a faithful, authentic way, using the original materials and trying to recover the unique atmosphere of these buildings without losing sight of the minimum comforts required by a tourism that seeks quality. It is precisely this genuine aspect what will attract European, American, and Asian tourists, to which high spending Moroccans are starting to capitalize on.

In this way, we find true architectural gems that are in operation and in perfectly preserved condition. A great example or of these restorations would be the Ait Ben Moro Kasbah in Skoura (Figure 4a) or the Cheikh Bassou ou Ali Kasbah in Tinghir (today Hotel Tomboctou).

We also find tourist accommodation in 'ksour', although these are less numerous, probably due to the difficulty of acquiring several adjoining properties to develop the activity. We have an 
exemplary case in the Ksar El Khorbat in Tibejdad. Precisely in this 'ksar', we find other particular preservation initiatives, coming from individuals interested in the maintenance of the ' $k$ sar' through the improvement of its general infrastructures. Thus, through International Cooperation projects, different actions have been carried out, such as a sanitation network, street paving, and the restoration of the entire city wall. These actions have stopped the exodus from the 'ksar' in addition to recovering its social and cultural life.

\subsection{Research Actions}

From the field of research, we can also contribute increased knowledge, therefore preserving this heritage. Within the actions carried out by the authors of the present contribution, we can distinguish two different methodologies: those based on graphic surveying, cataloging, analysis, and dissemination, and those that take advantage of educational actions for the restoration of a certain construction.

\subsubsection{Graphic Surveying, Cataloging, Analysis, and Dissemination}

The essential part of the research projects we have carried out in recent years is based on the analysis of the buildings themselves [15]. To pursue it, we have started with a specific graphical survey [16], with methodological characteristics adjusted to what we should study. In addition, we must take into account the difficulties of documenting the architecture in Morocco, since due to customs problems, we had to give up using many systems that would be essential elsewhere. In general, we are referring to any expensive or bulky equipment, such as 3D laser scanners or drones. To these limitations we must add those posed by the climate, where we can find below zero temperatures in the High Atlas 'ksour', while in the pre-Saharan area temperatures reach $50^{\circ} \mathrm{C}$.

Taking these initial limitations into account, we can classify the methodologies used in four categories according to the objective we wanted to achieve:

\section{Typological Study}

When working on an urban scale, we started with Google Earth satellite images as well as photogrammetric flights and cartography from the Institut Géographique National of Rabat. With this documentation, we visited the 'ksour', checking the general urban layout (streets and walls), while taking some large measurements to make the corresponding dimensional verification (Figure 5).

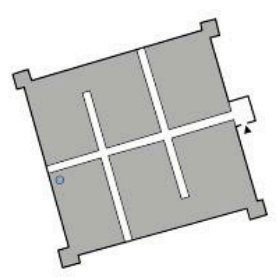

(a)

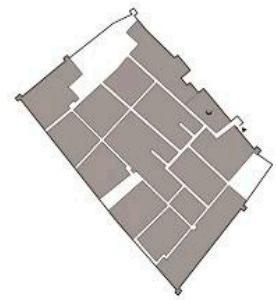

(b)

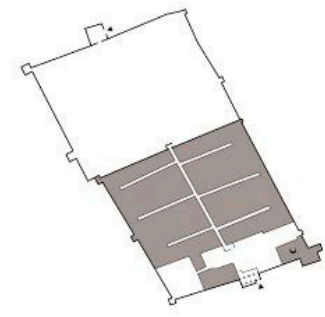

(c)

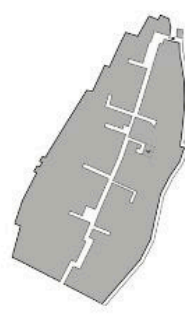

(d)

Figure 5. Ksour's ground floor plans: (a) Al-Zaouiat (Outat Valley); (b) Asrir (Mdagra Oasis); (c) Beni M'Hali (Mdagra Oasis); (d) Ait Ouafella (Outat Valley).

With these large-scale surveys we were able to carry out inventories, to later catalog based on the urban typologies found [17].

\section{Urban Study}

On a selection of the 'ksour' that were shown as archetypes of the various existing 'ksour', more detailed graphic surveys were carried out (Figure 6). In this case, the planimetry, elevations, 
and vertical sections have been drawn using direct measurements, that is, with a measuring tape. Occasionally, we assisted this survey with a total station that facilitated a support network to improve the accuracy of the graphic survey.
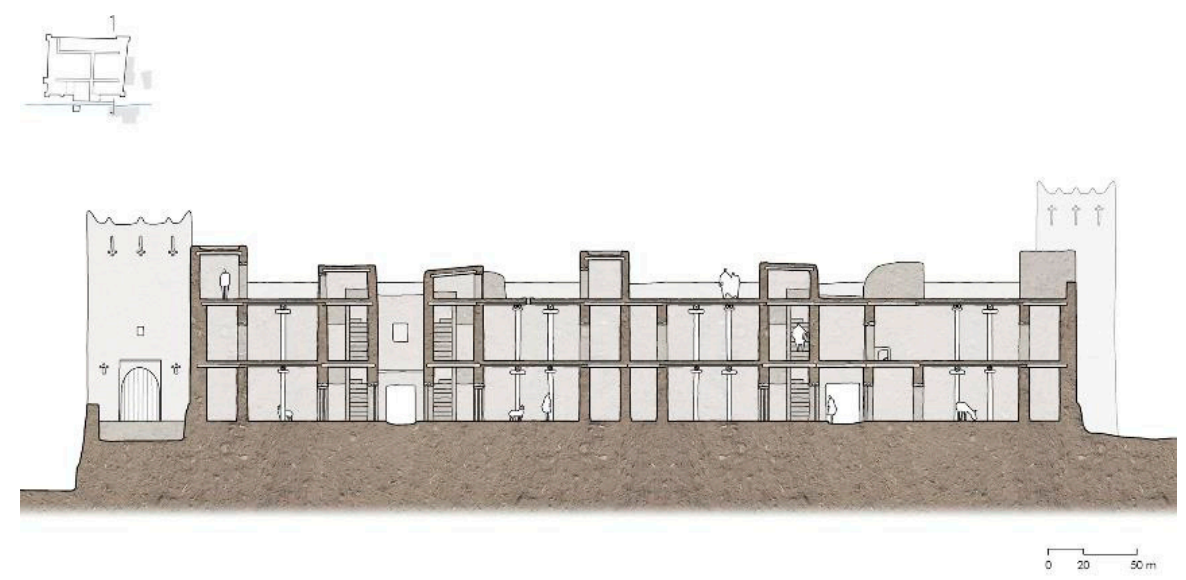

Figure 6. Tabenaatout Ksar. Section, Outat Valley.

Study by Units: Wall, Access, House, Mosque, Marabout, etc.

To define the different units that conform the constructions, we worked by means of direct surveying (Figure 7), complemented by the 3D multi-image photogrammetry (SfM) of those singular elements of difficult access (monumental doors, towers with battlements, etc.). Previously to these surveys, we performed a typological selection, that is, we chose a model by type among the existing ones, so that they served us for a global study. Thus, for example, we can analyze the types of entrances that respond to direct entrances, in elbow or zig-zag; or two-story dwellings, three-story or corner-dwellings with tower.

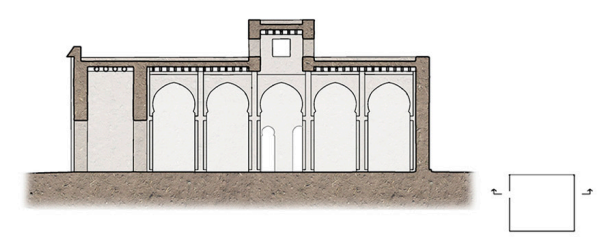

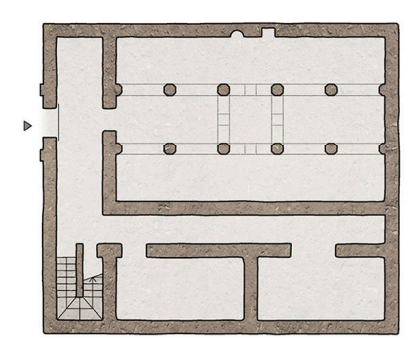

(a)
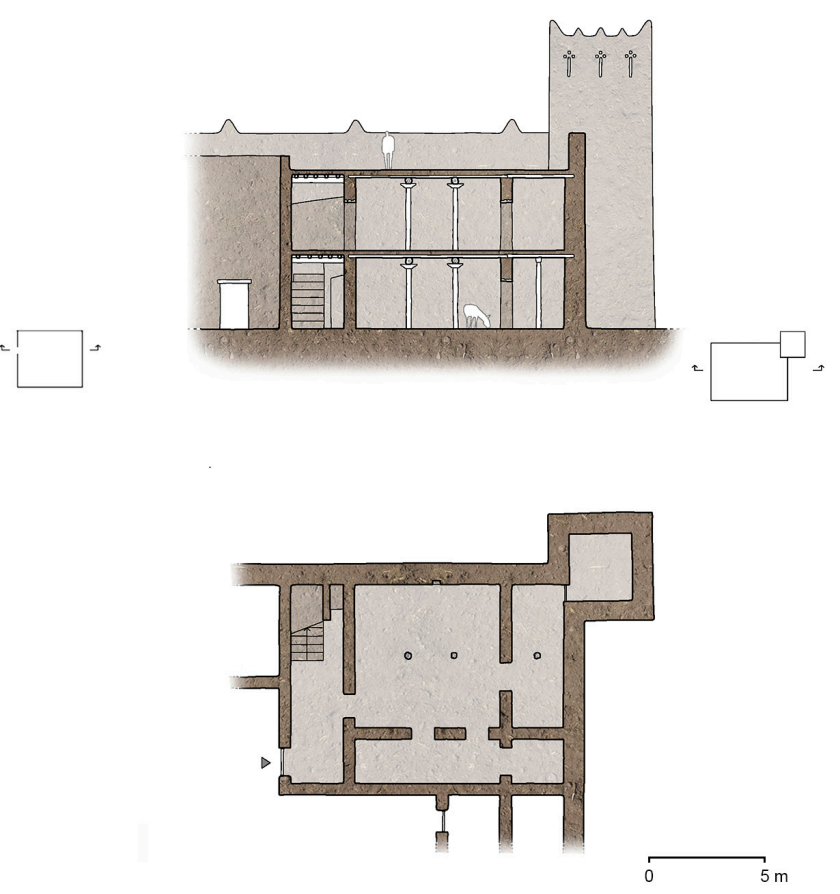

(b)

Figure 7. Graphic survey: (a) Tizuka Mosque, (Mdagra Oasis); (b) Dwelling at the Smoura Ksar (Outat Valley). 


\section{Reconstructive Hypotheses}

Some 'ksour' are in such an advanced state of deterioration that it is difficult to reconstruct their shape. However, we have used a method that has made it possible to obtain highly reliable virtual reconstructions $[18,19]$.

To carry out these reconstructions, we started out from a planimetric survey of all existing structures, mainly walls. With the support of a total station, we obtained a digital elevation model simultaneously. With this planimetry, and assisted by the elderly people of the place, we have been able to read the urban plot and even the extension sequence in some instances.

With these data, we will proceed to identify the constructive units, that is, observing the remains of a unit. Subsequently, we identify them with a unit of another 'ksar' from which we have its complete shape. Thus, if we have part of a tower we look for a complete one with that same shape, we model it and place it in the reconstruction, both in this tower and in those from which there are no remains. Similarly, we carry on with the door, wall, dwellings, patios, etc., obtaining a complete 3D model that we can integrate on the image of the archaeological site (Figure 8).

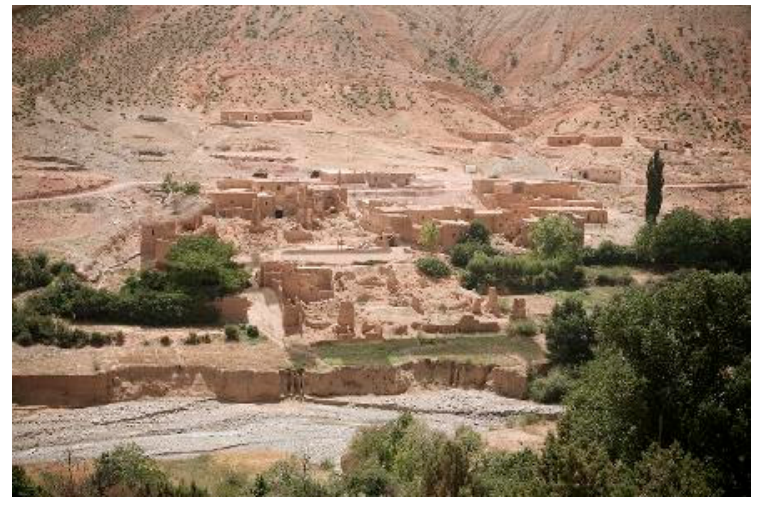

(a)

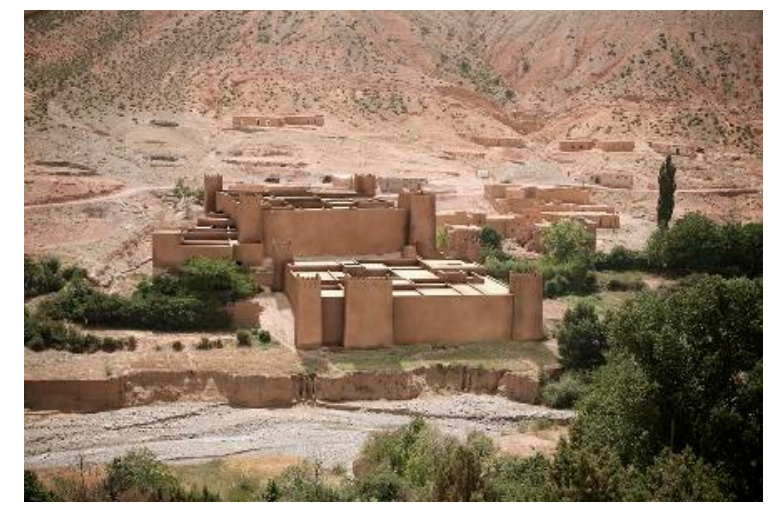

(b)

Figure 8. Tatiouine Ksar, Outat Valley. (a) At present; (b) Virtual reconstruction [20].

\section{Architectural Restoration Workshops}

A special case among the activities carried out in the frame of our research projects are the workshops on vernacular building techniques [21]. To conduct them, we choose some construction needing urgent restoration due to its risk status. This selection is based on the information and interest of the local authorities; otherwise we could not take action.

The process followed is: first, the construction or element on which to act is determined and a graphic survey [22] - which includes the detail of the construction system and the materials that must be used-is carried out. Then, the workshop is held with the participation of students who observe and document the restoration process conducted by local professionals, or 'maâlem', because there is nobody better than them to make the traditional construction techniques of their region known.

The result is greater knowledge of trades, which are also in danger of disappearing; deepening and dissemination of the study of a typology at risk; and the maintenance of the selected construction. We illustrate this with some images of the Sidi Bou Guertif Marabout, located in the town of Tinejdad, province of Er-Rachidia, within the Ferkla oasis, one of the greatest palm groves of Southern Morocco. In January 2016, on the occasion of a workshop scheduled within the Arquihabitat research project, we carried out its restoration.

To conduct this restoration workshop, two previous visits were made in 2012 and 2014, in the course of which we could already appreciate its rapid deterioration. When we returned in 2016 in order to carry out the restoration works, the deterioration was even greater, to the extent that the entire building was threatening to collapse. Damage was mainly concentrated in the vault (Figure 9), 
the walls, and the slab (Figure 10). The vault had lost part of its surface, and it was rebuilt using the same original material and system, that is, by means of rowlock adobe bricks without formwork. Its surface was then covered with a straw and mud mixture. The walls presented large fissures resulting from runoff. These fissures were sewn with keys of palm wood and then covered with successive straw and mud pounding. In the slab, loose earth was removed and both the supports of the palm beams and the different gaps that had appeared were consolidated (Figure 11). The rooftop was covered by a new layer of mud and straw mixture, reconstructing the slope to guarantee proper drainage.

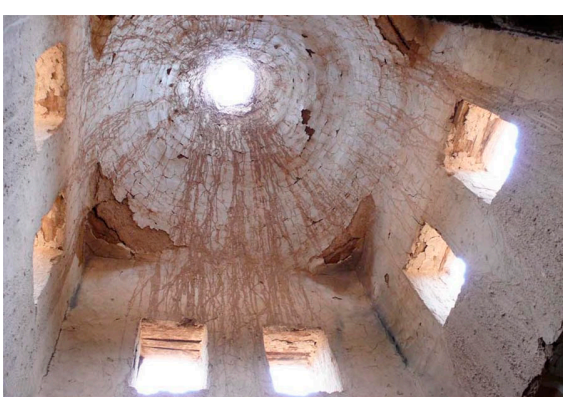

(a)

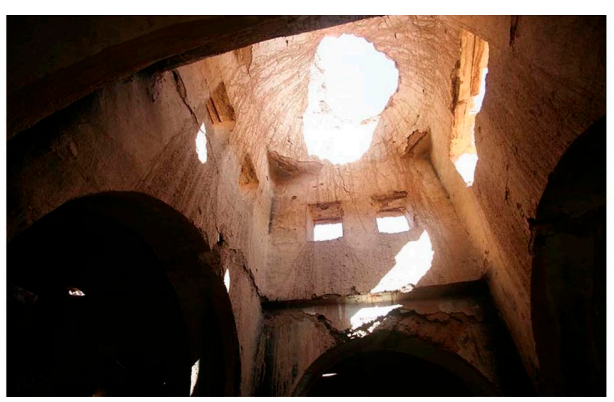

(b)

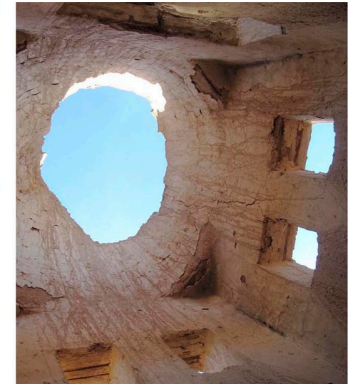

(c)

Figure 9. Sequence of the deterioration of the vault. Sidi Bou Guertif Marabout, Ferkla Oasis. (a) 2012; (b) $2014 ;$ (c) 2016 .
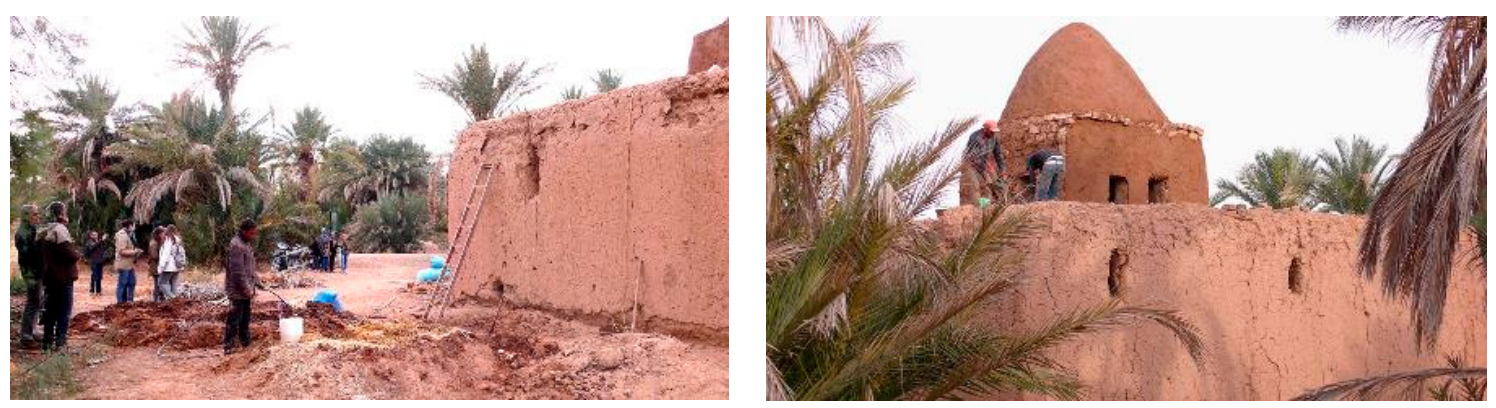

Figure 10. Restoration works of the marabout.

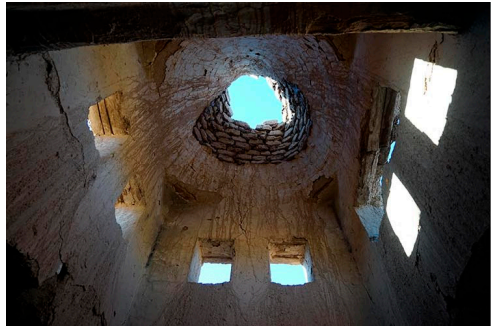

(a)

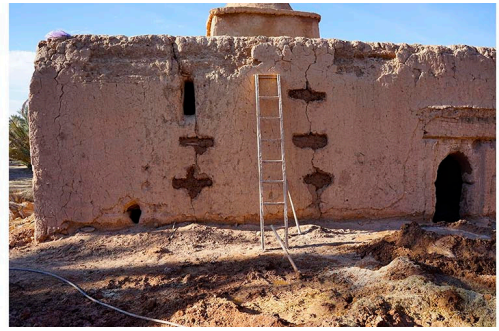

(b)

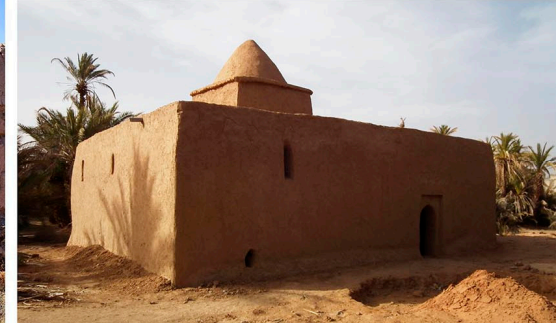

(c)

Figure 11. (a) Reconstruction works of the vault using adobe; (b) Sewing the wall with wooden keys; (c) Current status after restoration.

\section{Conclusions}

The reality of earth architecture of Southern Morocco in the 21st century is more than likely at risk of disappearance. Considered by many authors as one of the great cultural assets of Morocco, these traditional structures fulfill the concept of fortresses and are built with materials from their immediate surroundings. This architecture responds to aspects of social, defensive, and technological order, and adaptation to the environment and the landscape. It is definitely an organic and plastic architecture, 
worthy of multiple investigations in all its valleys and oases that should not be delayed over time. As we have commented previously, the changes produced in recent decades regarding the way of life of the local population are having a significant impact on these constructions, since in many cases they are being abandoned by those going to live in isolated buildings located outside of these cities, or migrating directly to the capitals. This abandonment results in a lack of maintenance and, ultimately, in an acceleration of the process of degradation leading to their demise.

Both the Moroccan administration and tourism entrepreneurs constitute a safeguard that, while praiseworthy, does not cover even a tiny proportion of the heritage in danger of collapse and disappearance. Thus, it seems that one of the best options would be documentation for better knowledge and dissemination, since it is certainly what will remain a few years from now.

As a result of our experience, we have determined graphic survey methodologies adapted to the reality of this country and specifically to this pre-desert environment, with which we continue working to guarantee the knowledge of this heritage. With them, we intend to contribute to the enhancement of the traditional earth architecture in Southern Morocco, promote its correct conservation and restoration, contribute to the valorization of the skilled trades of the traditional construction techniques and their materials and, ultimately, preserve this heritage at great risk of perishing forever.

Acknowledgments: The research project carried out in the Outat Valley and the research project carried out in the Ferkla Oasis "Arquihabitat" were funded by the Polytechnic University of Valencia, Spain.

Author Contributions: P.R.-N. directed the research project carried out in the Outat Valley and is a specialist in 3D graphic survey. T.G.P. directed the research project in the Ferkla Oasis and is a specialist in topographic surveys. Both are scholars of the history of Southern Morocco and specialists in earthen architecture. P.R.-N. directed the restoration work of the Sidi Bou Guertif Marabout. P.R.-N. and T.G.P. organized the structure of the paper, wrote it, and revised the final manuscript for subscription.

Conflicts of Interest: The authors declare no conflict of interest.

\section{References}

1. Laoust, E. L'habitation Chez les Transhumants du Maroc Central. L'igerm. Hespéris Tamuda; Larose: Paris, France, 1934; Volume XVIII, p. 110.

2. Nijst, A.L.M.T. Living on the Edge of the Sahara. A study of Traditional Forms of Habitation and Types of Settlement in Morocco; Government Publishing Office: Le Hague, France, 1973.

3. Terrasse, H. Kasbas Berbères de l'Atlas et Des Oasis; Editions des Horizons de France: Paris, France, 1938.

4. Cherradi, F. Earthen Architecture in Southern Morocco. In Rammed Earth Conservation; Taylor \& Francis Group: London, UK, 2012; pp. 487-491.

5. Marcais, W. L' Islamisme et la Vie Urbaine; Comptes Rendues des Seances de L'ACADEMIE des Inscriptions et Belles-Lettres: Paris, France, 1928; pp. 86-100.

6. Chueca Goitia, F. Breve Historia del Urbanismo; Alianza Editorial: Madrid, Spain, 1993.

7. Laoust, E. L'habitation chez les Transhumants du Maroc Central. La Maison", Heperies; Larose: Paris, France, 1932; Volume XIV, p. 137.

8. Sadki, A. Urbanisme et Dègradation de L'habitat Traditionnel des Oasis du Sud-Est Marocain: L'exemple Del Ksour u Tafilalt (Province d'Errachidia). Archi-Mag. Magazine de l'Architecture du Maghreb, 2009. Available online: http://www.archi-mag.com/essai_18.php (accessed on 4 December 2017).

9. Boussalh, M. CRATerre-ENSAG; Centre de Conservation et de Réhabilitation du Patrimoine Architectural Des Zones Atlassiques et Sub-Atlassiques. In Conservation Manual for Earth Architetecture Heritage in the Pre-Saharan Valleys of Morocco; CERKAS-Unesco Word Heritage Centre-CRA Terre-EAG: Ouarzazate, Morocco, 2005; pp. 9-17.

10. Ministère de L'habitat et de la Politique de la Ville, Programme d'Habitat Menaçant Ruine. Available online: http:/ / www.mhpv.gov.ma/?page_id=960 (accessed on 4 December 2017).

11. CERKAS. Available online: http:// cerkas.org/wordpress/ (accessed on 4 December 2017).

12. Kölbl, O.; Boussalh, M.; Fadli, B.; Larbi, B.; Naji, M.; Fadli, A. Synthèse de L'inventaire du Patrimoine Architectural de la Vallé du Dra. Ouarzazate; Ecole Polytechnique Fédérale de Lausanne et le CERKAS: Lausanne, Switzerland, 2010. 
13. AAVV. Inventaire du Patrimoine Architectural de la Vallée du Todra; CERKAS, Colegio de Aparejadores de Barcelona, Universidad Politécnica de Cataluña: Barcelona, Spain, 1999.

14. Casanovas, X. Rehabilitación y Acción Social en Marrakech, Marruecos. La Mejora de las Condiciones de Vida Tradicionales; Centre Méditerranéen de L'environnement Marrakech (CMEM): Marrakech, Morocco, 2008; p. 8.

15. Rodríguez-Navarro, P.; Gil Piqueras, T. Arquitectura de Tierra en Marruecos. El Valle del Outat en el Alto Atlas; Almed: Granada, Spain, 2015.

16. Gil Piqueras, T.; Rodríguez-Navarro, P. El levantamiento topográfico como método de puesta en valor del patrimonio arquitectónico: Dos proyectos en dos continents. In X Congreso Internacional de Expresión Gráfica Aplicada a la Edificación (APEGA 2010); Marfil S.A.: Alicante, Spain, 2010; pp. 509-518.

17. Rodríguez-Navarro, P.; Gil Piqueras, T. Inventario de los ksour del Valle del Outat en Marruecos. In Earthen Architecture. Past, Present and Future; Taylor \& Francis Group: London, UK, 2014; pp. 317-322.

18. Rodríguez-Navarro, P.; Fantini, P.F. The interpretation of archaeological persistence to generate digital 3D architectural typologies: The case of Ksar Tatiouine in the Moroccan High Atlas. In Proceedings of the International Conference on Cultural Heritage and New Technologies, Vienna, Austria, 14-16 November 2011; pp. 326-335.

19. Rodríguez-Navarro, P.; Fantini, P.F.; Gil Piqueras, T. Integrated methodology for urban survey and representation of the Morocco's High Atlas earth architecture. In Proceedings of the 2012 18th International Conference on Virtual Systems and Multimedia, Milan, Italy, 2-5 September 2012; pp. 637-640.

20. Gil Piqueras, T.; Rodríguez-Navarro, P. Lectura e interpretación de la evolución urbana del ksar Tatiouine. Hipótesis reconstructive. In XII Congreso Internacional de Expresión Gráfica Aplicada a la Edificación (APEGA 2014); Editorial Rueda: Madrid, Spain, 2014; pp. 131-139.

21. Rodríguez-Navarro, P.; Vidal, F.J.; Gil Piqueras, T. Earth construction techniques in the Northern High Atlas Morocco. In Rammed Earth Conservation; Taylor \& Francis Group: London, UK, 2012; pp. 569-574.

22. Rodríguez-Navarro, P.; Lillo Giner, S.; Gil Piqueras, T. Arquitectura de tierra en el Palmeral de el Khorbat (Marruecos). El morabito de Sidi Bou Guertif. In Arquitectura en Tierra. Patrimonio Cultural. XII CIATTI; Cátedra Juan de Villanueva, Universidad de Valladolid: Valladolid, Spain, 2015; pp. 60-66. 